\title{
Preliminary research on quantitative methods of water resources carrying capacity based on water resources balance sheet
}

\author{
Yanqiu Wang ${ }^{1}$, Xiaorong Huang ${ }^{1,2}$, Linyun Gao ${ }^{1}$, Biying Guo ${ }^{1}$, and Kai Ma ${ }^{1}$ \\ ${ }^{1}$ College of Water Resource \& Hydropower, Sichuan University, Chengdu 610065, China \\ ${ }^{2}$ State Key Laboratory of Hydraulics and Mountain River Engineering, \\ Sichuan University, Chengdu 610065, China \\ Correspondence: Xiaorong Huang (hxiaorong@scu.edu.cn)
}

Received: 30 December 2017 - Revised: 4 March 2018 - Accepted: 5 March 2018 - Published: 5 June 2018

\begin{abstract}
Water resources are not only basic natural resources, but also strategic economic resources and ecological control factors. Water resources carrying capacity constrains the sustainable development of regional economy and society. Studies of water resources carrying capacity can provide helpful information about how the socioeconomic system is both supported and restrained by the water resources system. Based on the research of different scholars, major problems in the study of water resources carrying capacity were summarized as follows: the definition of water resources carrying capacity is not yet unified; the methods of carrying capacity quantification based on the definition of inconsistency are poor in operability; the current quantitative research methods of water resources carrying capacity did not fully reflect the principles of sustainable development; it is difficult to quantify the relationship among the "water resources, economic society and ecological environment". Therefore, it is necessary to develop a better quantitative evaluation method to determine the regional water resources carrying capacity. This paper proposes a new approach to quantifying water resources carrying capacity (that is, through the compilation of the water resources balance sheet) to get a grasp of the regional water resources depletion and water environmental degradation (as well as regional water resources stock assets and liabilities), figure out the squeeze of socioeconomic activities on the environment, and discuss the quantitative calculation methods and technical route of water resources carrying capacity which are able to embody the substance of sustainable development.
\end{abstract}

\section{Introduction}

As a sort of irreplaceable natural resource, water resources are an essential element for human existence and an important guarantee for sustainable socioeconomic development. In China, a country experiencing an acute shortage of water, nearly two-thirds of cities are short of water to varying degrees (Chen, 2016) and the contradiction between water resources constraint and socioeconomic development is becoming increasingly prominent. As a result, control over the socioeconomic development and utilization intensity within the range of carrying capacity has become a core part of national efforts to guarantee water resources security in the future (Wang, 2017).
Most of the existing studies incorporate the carrying capacity of water resources into the theory of sustainable development, believing that economic development should be based on a virtuous cycle of the ecological environment, and the research should focus on the hydrology cycle process and mechanism under the natural - artificial binary mode with human interventions. Further, systematic consideration should be given to the relationship among "water resources, socioeconomy and ecological environment" (Zhu et al., 2002; Feng and Huang, 2008). The conclusions of several studies considered the fact that the carrying capacity of water resources signifies that water resources are needed to sustain a healthy social system (Cerutti et al., 2010; Bakker, 2012). However, current studies in this area lack depth. There are 
great difficulties in how to systematically quantify the relationship between the environment and the economy, as well as natural resources depletion and environmental degradation caused by economic activities (Gan et al., 2014). In recent years researchers have been paying more attention to the calculation methods of water resources carrying capacity rather than the theoretical research of water resources carrying capacity (Fu et al., 2012; Kang and $\mathrm{Xu}, 2012$ ). Hence, this paper proposes to bring water resources depletion and water environmental damage into the traditional national economic accounting system and establish a regional water resources balance sheet relying on studies on regional water resources assets and liabilities, so as to expand the quantitative channels for water resources carrying capacity.

\section{Concepts and research progress of water resources carrying capacity}

Carrying capacity, with its limit thought to be first derived from Aristotle and later applied as a mechanics index, refers to the maximum (extreme) carrying capacity of an object without causing any damage (Long et al., 2004). The earliest study on the carrying capacity of water resources in China was conducted in 1989 when Xinjiang Water Resources Soft Science Research Group carried out studies on Xinjiang's water resources carrying capacity and development strategies for the first time. Since 1990, many scholars have put forward numerous viewpoints, concepts, methods, evaluation index systems and calculation models related to the water resources carrying capacity, but no unified understanding has been formed so far (Zhao, 2009).

\subsection{Status quo of the research on water resources carrying capacity}

In general, definitions of water resources carrying capacity can be summarized into two schools of thought. The maximum support capacity theory represented by Shi Yafeng argued that water resources carrying capacity refers to the maximum capacity of water resources in a region to carry (accommodate) the agriculture, industry, city size and population without disruptions to the society and ecosystem, at a certain stage of the social, historic and technological development. It is a comprehensive objective changing with the development of the society, economy, and science and technology (Liu et al., 2011).

The maximum development capacity theory represented by $\mathrm{Xu}$ Youpeng argued that water resources carrying capacity refers to the maximum capacity of water resources to supply water for industrial and agricultural production, people's life, and the ecological environment under certain technical and economic level and social production conditions, i.e., the maximum development capacity of water resources. Water resources can be renewed naturally and constantly utilized by people, and bring benefits to mankind without causing any deterioration under this maximum development capacity (Xu, 1993).

Calculation methods for water resources carrying capacity are broadly divided into two categories. The first one is the evaluation method, which was designed to evaluate the degree of support for water resources to a certain scale of development through building an indicator system, such as the principal component analysis method (Fu and Ji, 1997), aggregative indicator method (Wang et al., 2000) and fuzzy evaluation method ( $\mathrm{Li}$ and Jin, 2009); the second one is the planning method, which was designed to take a large number of complex factors including economy, society, resources and environment as a whole to find out internal relations between them, and apply mathematical equations to simulate or build models, so as to figure out the optimal development plan, such as the system dynamics method (Yang et al., 2015) and multiobjective analysis method (Xue et al., 2000). In addition to these traditional quantitative methods, many scholars have made different attempts. For example, Feng et al. (2008) applied the water shortage risk assessment model based on information diffusion technologies to studies on the water resources carrying capacity and analyzed the water resources carrying capacity of Jinhua City, Zhejiang Province (Feng and Huang, 2008). Ren et al. (2016) put forward the regional water resources metabolism theory, which introduced the concept of biological metabolism to the water resources carrying capacity (Ren et al., 2016).

\subsection{Existing problems}

\subsubsection{The definition of water resources carrying capacity is not yet unified}

Water resources carrying capacity has been defined in two different ways. The former, taking the size of population and social economy that can be carried as an indicator of the water resources carrying capacity from the perspective of a water resources carrying object, namely, the socioeconomic system, is complete in terms of the physical meaning but comparatively abstract; while the latter, taking a specific volume such as water supply capacity as an indicator of the water resources carrying capacity from the perspective of water resources carrying subject, namely, the water resources system (Yuan et al., 2006), is incomplete in terms of the physical meaning but more intuitive. It is considered here that the former statement can better embody the substance of water resources carrying capacity and also have more practical significance.

\subsubsection{The methods of carrying capacity quantification based on the definition of inconsistency are poor in operability}

Two categories of calculation methods summed up in the above section can correspond respectively to two kinds of different definitions of the water resources carrying capacity. 
Due to the nonunified definitions, the results from the quantitative methods raised on the basis of different definitions are difficult to quantify and compare in reality, which leads to poor operability of these methods.

\subsubsection{Failure to fully reflect the principle of sustainable development}

The emphasis of research on water resources carrying capacity needs to persevere in the principle of sustainable development, but in general, the principle cannot be clearly reflected in the research process. The principle can only be implicitly reflected in researchers' research process according to their understanding of the connotation of sustainable development (Zhang et al., 2003). Consequently, the calculated results of the water resources carrying capacity can hardly reflect the depletion of resources and the loss of the environment.

\subsubsection{Bottlenecks, which are difficult to quantify, exist in the relationship among water resources, socioeconomy and ecological environment}

Studies on water resources carrying capacity at the present stage are generally conducted on water resources or social and economic activities as the main research objects only, which ignore the ecological environment and the internal relations between the trios. To do this, an optimal choice is to explore and compile a water resources balance sheet.

\section{Carrying capacity and water resources balance sheet}

\subsection{Concept of water resources balance sheet}

In 1946, John Richard Hicks, a British economist, put forward the green GDP idea for the first time, and he placed emphasis on changing the perception of pure economic growth (Zhang, 2006). In the mid-1990s, the loss caused by ecological environment destruction every year in China accounted for more than $8 \%$ of GDP (Chen, 2007), indicating that the economic development comes at the expense of the environment and the extensive development model has brought serious negative impact to the ecological environment. When economic prosperity comes with serious environmental damage and health hazards, the false image of national growth emerges, which will cause distortion or twist to the evaluation of resources carrying capacity. Hence, clarification of the creditor relationship between the environment and the economy can play a key role in calculating water resources carrying capacity.

What is water resources liability? Generalized water resources liabilities can be defined as the negative impact on water resources volume, environmental quality and ecosystem function due to excessive improper economic activities. It could be further described as the overuse of water resources leading to the damage of water cycling process and renewability of water, the overdischarge of wastewater and pollutants to natural water bodies leading to the reduction of environmental capacity, and the excessive consumption of ecological water use leading to the decrease of ecosystem service (Jia et al., 2017). As the human society attaches importance to the ecological environment and sustainable development, the US, Canada, Japan, Australia and other countries have conducted research on the water resources balance sheet. Since China carried out the green GDP accounting study in the early 21 st century, natural resources assets accounting has begun to be put into practice. National balance sheet is subject to the System of National Accounts (SNA), and so the System of Integrated Environmental and Economic Accounting (SEEA) jointly launched by the United Nations and the World Bank as an auxiliary accounting system to SNA, is considered to be comprised of the current international norms which are closest to the compilation of China's natural resources balance sheet (NRBS) (Geng et al., 2015). On this basis, the United Nations Statistics Division cooperated with the London Group on Environmental Accounting in compiling the System of Environmental and Economic Accounting for Water (SEEAW) based on SEEA, and China also formed the general framework of Comprehensive System of Environmental and Economic Accounting for Water (CSEEAW) (Chai et al., 2016) in 2009.

However, the SEEAW did not set specific liability items, and that is why it differs from the water balance sheet (Huang, 2017). Therefore, the decision on whether or not to recognize water resources liabilities determines the compilation of the statement of water resources assets and liabilities or water resources assets balance. So, is there any water resources liability? It can be seen that the resources depletion, environmental damage and ecological disruption caused by current socioeconomic development represent a sort of "debt" to natural resources, which could clearly reflect the "accounting" based on the concept of sustainable development. The environment should be treated as a virtual subject to specify water resources equities and liabilities of the economy, so as to restore and compensate the environment (Jia et al., 2017).

The system of accounting for the water resources balance sheet shall include various statement forms and design the order in accordance with the statement forms as follows: physical object first, value second; stock first, flow second; classification first, consolidation second, which includes the physical accounts of water resources, the quality accounts of water resources, and the hybrid supply and use table. Finally, the compilation of water resources balance sheet could be completed on the basis of the accounting for water resources magnitude of value. In the System of Trial Preparation of Natural Resources Balance Sheet (Preparation Guide) published in November 2015, China has come up with the standard statement forms of the physical accounts of water resources and the quality accounts of water resources. How- 
Table 1. Basic statement form of the water resources equity balance sheet.

\begin{tabular}{|c|c|c|c|c|c|c|c|c|}
\hline \multirow[t]{2}{*}{ Item } & & \multirow{2}{*}{$\begin{array}{l}\text { Opening } \\
\text { stock }\end{array}$} & \multirow{2}{*}{$\begin{array}{l}\text { Equity } \\
\text { distribution }\end{array}$} & \multirow{2}{*}{$\begin{array}{l}\text { Equity } \\
\text { use }\end{array}$} & \multicolumn{3}{|c|}{ Current net change } & \multirow{2}{*}{$\begin{array}{l}\text { Closing } \\
\text { stock }\end{array}$} \\
\hline & & & & & $\begin{array}{l}\text { Equity } \\
\text { assets }\end{array}$ & $\begin{array}{l}\text { Equity } \\
\text { liabilities }\end{array}$ & $\begin{array}{l}\text { Net equity } \\
\text { assets }\end{array}$ & \\
\hline Water resources & $\begin{array}{l}1 \text { Surface water } \\
2 \text { Groundwater } \\
3 \ldots \\
4 \text { Total }\end{array}$ & & & & & & & \\
\hline Water environment & $\begin{array}{l}5 \text { COD discharge } \\
6 \text { Ammonia nitrogen } \\
\text { discharge } \\
7 \ldots \\
8 \text { Total }\end{array}$ & & & & & & & \\
\hline Water ecology & $\begin{array}{l}9 \text { Ecological water } \\
\text { demand } \\
10 \text { Sea inflow } \\
11 \ldots \\
12 \text { Total }\end{array}$ & & & & & & & \\
\hline
\end{tabular}

Note: there is a balance relationship in the table, i.e., equity assets - equity liabilities = net equity assets; the Three Red Lines index can be used as a reference for equity distribution. Due to data limitations, the compilation of water environment and water ecology is very difficult at the present stage.

Explanation of some conceptions: (1) opening stock - can be set to zero in the beginning of the accounting year; meanwhile the ending stock represents the changes in the current period. (2) Equity distribution - distribution quota that based on the Three Red Lines index or assessment indicators, which generally refers to the multiyear average. (3) Equity use - water consumption during the accounting period. (4) Equity assets - the rights and benefits of water users under the legal protection during water consumption. (5) Equity liabilities - obligation of water users to compensate or repair the environment due to exceeding the rights stipulated by law during the water consumption.

ever, current studies on the value of water resources are not well developed. Hence the standards for statement forms of water resources balance sheet have not yet been unified. The research achievements of Hong Gan, Lin Wang, ChangHai Qin, and Lin Jia are referred here to list the basic statement form of the water resources equity balance sheet (Chai et al., 2016; Zhou et al., 2017); see Table 1.

It can be seen that the inclusion of resources depletion, environmental damage and ecological benefits in the system of evaluation for socioeconomic development can establish a system of national economy accounting in favor of green and low-carbon cyclic development. Problems about the water resources carrying capacity at this stage are due to the lack of quantification of resource depletion and environmental damage. Hence, if these two can be connected, then deficiencies in the quantification of water resources carrying capacity may be improved.

\subsection{Discussion on quantification methods}

The concept of water resources carrying capacity is related to a huge and complex system with many factors such as population, resource, environment, ecology, society, economy and technique, while the previous calculation of the carrying capacity usually failed to consider the interaction among various factors in the complex system. In order to solve the problem that the current research has ignored the inherent relationship among water resources, economic so- ciety and ecological environment, the feedback relationship among the water resources system, socioeconomic system and ecological environment system is analyzed and summarized as shown in Fig. 1.

It is observed that the physical accounts of water resources clearly reflects the increase (source) and decrease (outflow) in stock of regional water resources in each year, in accordance with the feedback relationship between the water resources system (supply) and socioeconomic system (depletion). And the accounting of assets and liabilities for water resources, water environment and water ecology in the water resources balance sheet can reflect the depletion and degradation of the ecological environment caused by regional socioeconomic water utilization. Therefore, an attempt is made to combine these two with the quantification of the carrying capacity, to avoid the twisting or distortion of the calculation of water resources carrying capacity, and propose the technical route for quantification of the carrying capacity as shown in Fig. 2.

Studies on water resources valuation at the present stage are inadequate. Consequently, the discussion here is based on the physical water assets account, in which the consideration may be given to deduct water liabilities (i.e., the equity liability item in Fig. 1) from the available water resources for compensation for water liabilities. It can be seen that the combination with the water resources balance sheet can more completely reflect the endowment conditions of a regional water resources circulation system, the resource threshold 


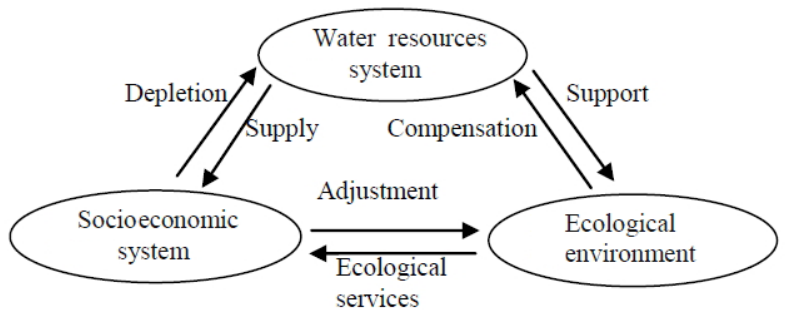

Figure 1. System feedback diagram.

that can be provided facing the economic development pressure and the water resources constraint after generating the liabilities, as well as avoid the distortion of evaluation results. Meanwhile, water resources liability items reflect the resources depletion and environmental degradation resulting from social and economic activities and lay a foundation for maintaining a virtuous ecological cycle. And the quantification of water resources carrying capacity on this basis is able to fully reflect the sustainable development theory.

\section{Case study and discussion}

\subsection{Calculation of water resources carrying capacity in Chengdu}

Due to its abundant amount of data and the good foundation of previous research, Chengdu was selected as the study area. Chengdu, located in central Sichuan at $102^{\circ} 54^{\prime}-104^{\circ} 53^{\prime} \mathrm{E}$ and $30^{\circ} 05^{\prime}-31^{\circ} 26^{\prime} \mathrm{N}$, covers an area of $12390 \mathrm{~km}^{2}$ in total. Chengdu has a moderate subtropical monsoon climate and abundant precipitation, with the annual average precipitation ranging from 900 to $1300 \mathrm{~mm}$ and multiple years of total water resources reaching 8.607 billion $\mathrm{m}^{3}$. In general, Chengdu boasts abundant water resources, which mainly come from the plentiful transit water resources in the region, while Chengdu does not have rich local water resources due to a dense population and relatively little per capita water resources.

According to the above quantization technology route, the water resources capacity of Chengdu city in 2015 is calculated as follows. The data are from the Chengdu Water Resources Bulletin (Chengdu Water Authority, 2015) and some relevant reports. Taking the multiyear average of 1980-2005 groundwater in Chengdu at 9.720 billion $\mathrm{m}^{3}$ as the beginning stock and the year of 2015 as the beginning year, the physical accounts of water resources of Chengdu in 2015 (see Table 2) is compiled with reference to the trial compilation achievement of Xi Yuanyuan (Xi, 2017) and the compilation requirements of the System of Trial Preparation of Natural Resources Balance Sheet (Preparation Guide). Meanwhile, the "Three Red Lines" control objectives of all districts in Chengdu are combined to compile the water resources items in the statement of water resources equity balance sheet of Chengdu in 2015, see Table 3. Due to data limitations, the water environment and water ecology items are not filled in here.

Total available regional water resources are determined according to the method set out in the Technical Details of $\mathrm{Na}$ tional IWRM Planning. The formula is as follows:

$W=W_{0}-W_{S}+W_{T}$,

where $W$ refers to the total available regional water resources, $W_{0}$ refers to the total water resources, $W_{s}$ refers to the ecological water demand and $W_{T}$ refers to the water resources diverted in from outside the region, all measured in 100 million $\mathrm{m}^{3}$. According to the meaning of each item in the physical accounts of water resources, it can be seen that the total water resources corresponds to the value in the third row of the first column in the Table 2, expressed as $[3,1]$, meanwhile there is a balance relationship, i.e., $[3,1]=[3,2]+[3$, $3]$. The water resources diverted in from the outside region corresponds to the value in the sixth row of the first column in the Table 2, expressed as $[6,1]$.

The ecological water demand can be calculated in accordance with the method set out in the Estimation Method of Available Water Resources (Trial) by the Ministry of Water Resources of China. With the percentage of multiyear average regional runoff (10-20\% for northern areas and $20-30 \%$ for southern areas generally) as the minimum ecological water demand of rivers, here the ecological water demand is calculated at $20 \%$, deriving the result of ecological water demand of 2.996 billion $\mathrm{m}^{3}$.

$W=[3,1]+[6,1]-29.96$

Thus, the total available water resources of Chengdu in 2015 stood at 3.853 billion $\mathrm{m}^{3}$ by calculation.

According to the Statistical Yearbook of Chengdu (Chengdu Bureau of Statistics, 2016), the per capita water consumption $A_{1}$ is calculated by extracting water consumption of domestic, industrial, agricultural and ecological water outside the channel from the physical accounts of water resources.

$A_{1}=\frac{[12,1]}{P(t)}=\frac{[13,1]+[14,1]+[15,1]+[16,1]}{P(t)}$,

where $P(t)$ corresponds to the total population in the corresponding year; the value of numerators derive from Table 2 . Thus the per capita water consumption of Chengdu in 2015 is $358 \mathrm{~m}^{3}$ by calculation. The total available water resources in the corresponding year divided by the per capita water consumption derives the water resources carrying capacity of that year. The overcarrying is calculated using the following formula (Wang et al., 2007) to measure the overcarrying of regional water resources.

$R=\frac{A_{1} \times P(t)}{W}$

When $R<1$, it is not overcarrying, and the smaller the value is, the greater the potential carrying capacity is; when $R>1$, 


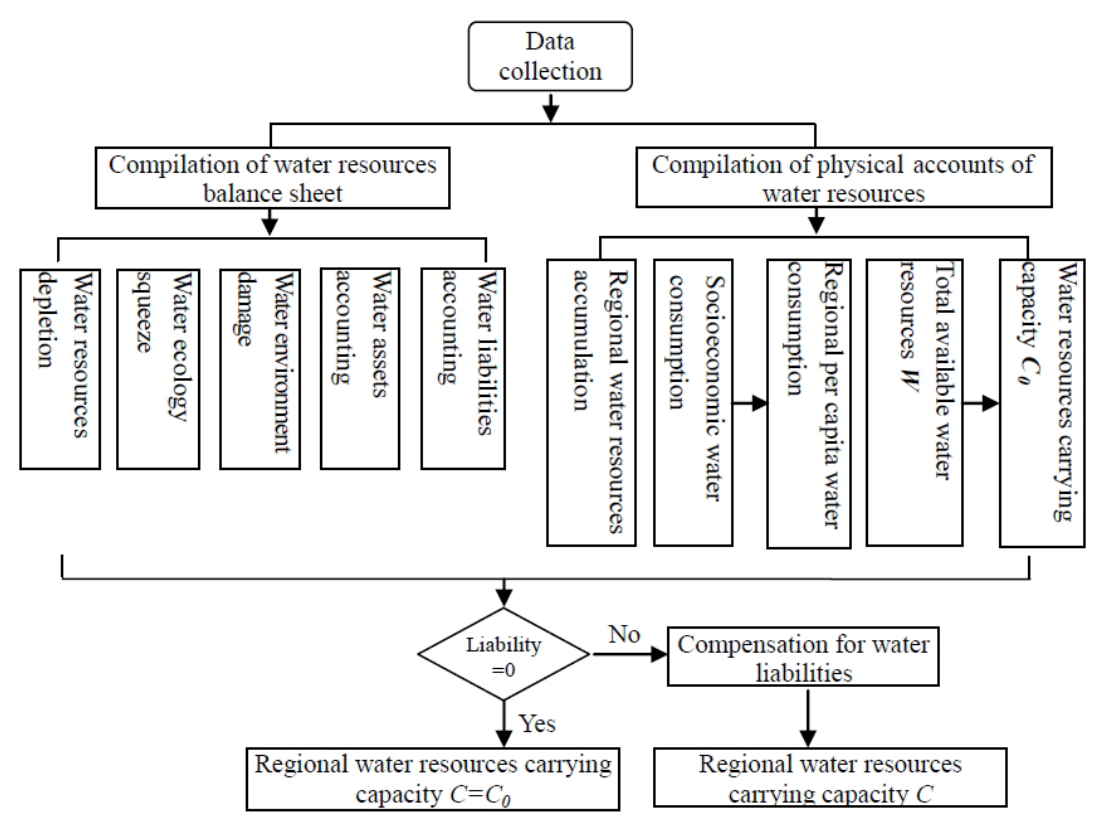

Figure 2. Technical route of carrying capacity quantification.

Table 2. The physical accounts of water resources of Chengdu in 2015 , measured in units of 100 million $\mathrm{m}^{3}$.

\begin{tabular}{|c|c|c|c|c|}
\hline Indicator & Code & Total & Surface water & Groundwater \\
\hline A & B & 1 & 2 & 3 \\
\hline Opening stock & 1 & 99.13 & 1.93 & 97.20 \\
\hline Increase in stocks & 2 & 324.35 & 296.57 & 27.78 \\
\hline Water resources from rainfall & 3 & 66.32 & 41.48 & 24.84 \\
\hline Inflows and diverted in & 4 & 235.36 & 232.42 & 2.94 \\
\hline Inflows from outside region & 5 & 205.92 & 205.92 & - \\
\hline Diverted in from outside region & 6 & 2.17 & 2.17 & - \\
\hline Inflows from other water bodies & 7 & 27.27 & 24.33 & 2.94 \\
\hline Socioeconomic return water & 8 & 22.67 & 22.67 & - \\
\hline Irrigation return water & 9 & 11.62 & 11.62 & - \\
\hline Nonirrigation return water & 10 & 11.05 & 11.05 & - \\
\hline Decrease in stocks & 11 & 326.05 & 296.59 & 29.46 \\
\hline Water consumption & 12 & 52.44 & 49.7 & 2.74 \\
\hline Domestic & 13 & 9.26 & - & - \\
\hline Industrial & 14 & 15.96 & - & - \\
\hline Agricultural & 15 & 25.69 & - & - \\
\hline Ecological water outside the channel & 16 & 1.53 & 1.53 & - \\
\hline Outflows and diverted out & 17 & 268.99 & 244.66 & 24.33 \\
\hline Outflows to outside region & 18 & 213.73 & 213.73 & - \\
\hline Diverted out to outside region & 20 & 27.99 & 27.99 & - \\
\hline Outflows to other water bodies & 21 & 27.27 & 2.94 & 24.33 \\
\hline Nonwater consumption & 22 & 4.62 & 2.23 & 2.39 \\
\hline Closing stock & 23 & 97.43 & 1.91 & 95.52 \\
\hline
\end{tabular}

Note: the nonwater consumption in the table refers to the evaporation losses of the lakes and reservoirs, the loss of drainage evaporation and the evaporation of underground water. However, due to the current state of monitoring technology, this indicator cannot be obtained by calculation or evaluation. Therefore it is treated as a balancing item to keep the entire table in balance. Definitions of other indicators refer to Chengdu Water Resources Bulletin. 
Table 3. Water resources equity balance sheet of Chengdu in 2015 , measured in units of 100 million $\mathrm{m}^{3}$.

\begin{tabular}{|c|c|c|c|c|c|c|c|c|}
\hline \multirow[t]{2}{*}{ Item } & & \multirow{2}{*}{$\begin{array}{l}\text { Opening } \\
\text { stock }\end{array}$} & \multirow{2}{*}{$\begin{array}{r}\text { Equity } \\
\text { distribution }\end{array}$} & \multirow{2}{*}{$\begin{array}{r}\text { Equity } \\
\text { use }\end{array}$} & \multicolumn{3}{|c|}{ Current net change } & \multirow{2}{*}{$\begin{array}{r}\text { Closing } \\
\text { stock }\end{array}$} \\
\hline & & & & & $\begin{array}{l}\text { Equity } \\
\text { assets }\end{array}$ & $\begin{array}{r}\text { Equity } \\
\text { liabilities }\end{array}$ & $\begin{array}{r}\text { Net equity } \\
\text { assets }\end{array}$ & \\
\hline \multirow[t]{3}{*}{ Water Resources } & 1 Surface water & - & 55.14 & 49.7 & 5.44 & 0 & 5.44 & 5.44 \\
\hline & 2 Groundwater & - & 3.76 & 2.74 & 1.02 & 0 & 1.02 & 1.02 \\
\hline & 3 Total & - & 59.9 & 52.44 & 6.46 & 0 & 6.46 & 6.46 \\
\hline
\end{tabular}

the region is in the overcarrying state, and the greater the value is, the more serious the overcarrying is.

The water resources carrying capacity of Chengdu in 2015 is calculated as shown in Table 4 . It can be seen that Chengdu did not generate water resources liability in 2015 , but water resources were in the overcarrying state. Therefore, it is necessary to strengthen water conservation, tighten up pollution control and speed up the industrial restructuring, so as to guarantee the ecological environmental water demand and improve the water resources carrying capacity appropriately.

\subsection{Discussion}

The results of the discussion are as follows.

1. Table 2 shows that the groundwater extraction in 2015 was 274 million $\mathrm{m}^{3}$, less than the target of 376 million $\mathrm{m}^{3}$ controlled by the Three Red Lines index in 2015 in Chengdu. And the total amount of water used was 5.244 billion $\mathrm{m}^{3}$, which did not exceed the target of 5.990 billion $\mathrm{m}^{3}$ in the Three Red Lines index in 2015 in Chengdu. Therefore, it can be seen from Table 3 that no water equity liabilities have been generated in Chengdu in 2015 .

2. The proportion of the total amount of agricultural water in Table 2 is the largest, accounting for $48.99 \%$ of the total, followed by industrial water consumption, accounting for $30.43 \%$. Ecological water outside the channel takes up $2.92 \%$. It can be seen that most of the water used in Chengdu was agricultural water, followed by industrial water consumption, which is only about half of agricultural water.

3. Table 4 shows that the water resources carrying capacity of Chengdu in 2015 was 10762600 persons and the overcarrying state was 1.36 . Through observing the structure of water consumption in Chengdu, it is suggested that the water resources carrying capacity of Chengdu should be improved appropriately by increasing the utilization rate of industrial and agricultural water in Chengdu.

4. Compared with other research (Guo, 2013), which calculated the water resources carrying capacity of
Table 4. Water resources carrying capacity of Chengdu in 2015.

\begin{tabular}{lr}
\hline Item & 2015 \\
\hline Total water resources $\left(100\right.$ million $\left.\mathrm{m}^{3}\right)$ & 66.32 \\
Total population $(10000$ persons $)$ & 1465.8 \\
Total available water resources $W\left(100\right.$ million $\left.^{3}\right)$ & 38.53 \\
Per capita water consumption $\left(\mathrm{m}^{3}\right)$ & 358 \\
Water resources carrying capacity $C(10000$ persons $)$ & 1076.26 \\
Water resources liabilities $\left(100\right.$ million $\left.^{3}\right)$ & 0 \\
Water resources carrying capacity $C(10000$ persons $)$ & 1076.26 \\
Overcarrying & 1.36 \\
\hline
\end{tabular}

Chengdu in 2015 was 11949500 persons by the system dynamics, its results are close to the results calculated through the above technical route. Since the above technical route takes into account whether the economic society will generate liabilities in terms of water resources depletion, it can better reflect the connotation of water resources carrying capacity and embody the sustainability theory compared with the traditional methods. In addition to calculating the regional water resources carrying capacity, the idea of this article can also be used to calculate the water environmental capacity of the area in combination with the quality accounts of water resources.

\section{Conclusions}

The conclusions to this study are as follows.

1. Compared to the past achievements, Chengdu's water resources carrying capacity calculated by the above technical route is reasonable and practical. However, the water environment and water ecological liabilities were not taken into account due to the limitation of data at this stage, and thus the result can not reflect water environmental damage and water ecology squeeze. Subsequent further studies are needed for improvement.

2. The approach to quantifying water resources carrying capacity through the compilation of the water resources balance sheet is feasible. However, the compilation of the water resources balance sheet needs further 
research, focusing on studying how to value the water resources, and replenishing two indicators in terms of water environment and water ecology, so as to optimize and expand the quantitative methods of water resources carrying capacity.

Data availability. The data used in this article are from the Chengdu Water Authority (2015; http://www.cdwater.gov.cn/wsbs/ bmcx/sl/system/2017/03/1/000002497.html) and the Chengdu Bureau of Statistics (2016; http://www.cdstats.chengdu.gov.cn/htm/ detail_63038.html)

Competing interests. The authors declare that they have no conflict of interest.

Special issue statement. This article is part of the special issue "Innovative water resources management - understanding and balancing interactions between humankind and nature". It is a result of the 8th International Water Resources Management Conference of ICWRS, Beijing, China, 13-15 June 2018.

Acknowledgements. This study was supported by the National Science Foundation of China grants 51779160 and 51579161.

Edited by: Zongxue Xu

Reviewed by: two anonymous referees

\section{References}

Bakker, K.: Water management, Water security: research challenges and opportunities, Science, 337, 914, https://doi.org/10.1126/science.1226337, 2012.

Cerutti, A. K., Bagliani, M., Beccaro, G. L., and Bounous, G.: Application of Ecological Footprint Analysis on nectarine production: methodological issues and results from a case study in Italy, J. Clean. Prod., 18, 771-776, 2010.

Chai, X. R., Huang, X. R., Xi, Y. Y., and Yang, P. P.: Analysis on preparation of water resources balance sheet, Journal of Water Resources and Water Engineering, 27, 44-49, 2016.

Chen, L.: National implementation of double-control action on total water consumption and intensity strive to ensure sustained and healthy economic and social development, China Water Resources, 23, 21-24, 2016.

Chen, Z. Z.: Promote ecological science with enthusiasm and truthseeking spirit, Resources Environment and Development, 2, 1-2, 2007.

Chengdu Bureau of Statistics: The Statistical Yearbook of Chengdu, available at: http://www.cdstats.chengdu.gov.cn/htm/ detail_63038.html (last access: 26 March 2018), 2016.

Chengdu Water Authority: Chengdu Water Resources Bulletin, available at: http://www.cdwater.gov.cn/wsbs/bmcx/sl/system/ 2017/03/1/000002497.html (last access: 26 March 2018), 2015.
Feng, L. H. and Huang, C. F.: A risk assessment model of water shortage based on information diffusion technology and its application in analyzing carrying capacity of water resources, Water Resources Management, 22, 621, https://doi.org/10.1007/s11269-007-9182-z, 2008.

Fu, Q., Jiang, Q., and Wang, Z.: Comprehensive Evaluation of Regional Agricultural Water and Land Resources Carrying Capacity Based on DPSIR Concept Framework and PP Mode, Springer Berlin Heidelberg, Germany, 370, 391-398, 2012.

Fu, X. and Ji, C. M.: A multi-dimension DP Model and application, Water Resources and Power, 4, 1-6, 1997.

Gan, H., Wang, L., Qing, C. H., and Jia, L.: Understanding of balance sheet of water resources, China Water Resources, 14, 1-7, 2014.

Geng, J. X., Hu, T. Y., and Liu, Z. J.: The research on preparation and application of Chinese National Balance Sheet and Natural Resources Balance Sheet - An Analysis Based on SNA 2008 and SEEA 2012, Accounting Research, 1, 15-24, 2015.

Guo, W.: Dynamic Simulation Analysis of Water Resources Population Carrying Capacity Based on System Dynamics - A Case Study of Chengdu, Journal of Henan Science and Technology, 16, 176-177, 2013.

Huang, X. R.: Perspective on theories and methods study the compilation of water resources balance sheet, Journal of Water Resources and Water Engineering, 28, 1-5, 2017.

Jia, L., Gan, H., and Wang, L.: Discussion on water resources liabilities, Journal of Natural Resources, 32, 1-11, 2017.

Kang, P. and Xu, L.: Water Environmental Carrying Capacity Assessment of an Industrial Park, Procedia Environ. Sci., 13, 879890, 2012.

Li, G. and Jin, C. L.: Fuzzy comprehensive evaluation for carrying capacity of regional water resources, Water Resour. Manag., 23, 2505-2513, 2009.

Long, T. R., Jiang, W. C., and He, Q.: Water resources carrying capacity: new perspectives based on eco-economic analysis and sustainable development, J. Hydraul. Eng., 35, 38-45, 2004.

Ren, C., Guo, P., and Li, M.: An innovative method for water resources carrying capacity research-metabolic theory of regional water resources, J. Environ. Manage., 167, 139-146, 2016.

Liu, J. J., Dong, S. C., and Li, Z. H.: Comprehensive Evaluation of Chinese Water Resources Carrying Capacity, J. Nat. Resour., 26, 258-269, 2011.

Wang, D. X., Wang, H., and Ma, J.: Water resources supporting capacity for regional development in China, J. Hydraul. Eng., 11, 21-26, 2000.

Wang, J. H.: Evaluation and strategic allocation of national water resources carrying capacity, Chin. J. Environment Management, 9, 111-112, 2017.

Wang, Z. J., Liao, S. H., Wu, X. F., Zhao, J. S., and Gan, H.: Water resources carrying capacity in Datong city, South-to-North Water Diversion and Water Science \& Technology, 5, 47-50, 2007.

$\mathrm{Xi}, \mathrm{Y}$. Y.: The research of physical asset account for water resources in Chengdu, Sichuan University, Sichuan University Press, 2017.

$\mathrm{Xu}$, Y. P.: A study of comprehensive evaluation of the water resources carrying capacity in the arid area-a case study in the Hetian river basin of Xinjiang, Journal of Natural Resources, 8, 229237, 1993. 
Xue, X. J., Hui, Y. H., and Huang, Q.: Research on city water resources capacity and its practical example, Journal of Northwest A\&F University, 28, 135-139, 2000.

Yang, J., Lei, K., and Khu, S.: Assessment of water environmental carrying capacity for sustainable development using a coupled system dynamics approach applied to the Tieling of the Liao river basin, Environ. Earth Sci., 73, 5173-5183, 2015.

Yuan, Y., Gan, H., Wang, Z. J., and Bao, W. F.: Discussion on progress and development trend of the research on water resources carrying capacity, Journal of China Institute of Water Resources and Hydropower Research, 4, 62-67, 2006.

Zhang, L.: Research on forest resources accounting of green GDP, Harbin Institute of Technology, 2006.
Zhang, L., Dong, Z. C., and Zhang, W.: Progress and prospect of research of water resources capacity, Water Resources and Hydropower Engineering, 34, 1-4, 2003.

Zhao, N.: The empirical research of Beijing water resources carrying capacity and pressure state, Urban Stud., 8, 148-152, 2009.

Zhou, P., Jia, L., and Gan, H.: The framework of physical water resources accounting for water entities, Accounting Research, 2017, 24-31, 2017.

Zhu, Y.Z., Xia, J., and Tan, G.: A primary study on the theories and process of water resources carrying capacity, Progress in Geography, 21, 180-188, 2002. 